\title{
Effect of Gasoline-AVGAS Blends on Engine Performance of Engine with Direct Injection
}

\author{
İbrahim Doğan ${ }^{1, *(\mathbb{D})}$, Mehmet Selman Gökmen ${ }^{2}$, Hasan Aydogan ${ }^{3}$ \\ ${ }^{1}$ Selçuk University, Institute of Science, Departmant of Mechanical Engineering, Konya, Turkey. \\ ${ }^{2}$ Necmettin Erbakan University, Seydişehir Vocational School, Automotive Tech. Prog., Konya, Turkey. \\ ${ }^{3}$ Selçuk University, Faculty of Technology, Department of Mechanical Engineering, Konya, Turkey.
}

\author{
Article History \\ Received 28 May 2021 \\ Accepted 06 September 2021 \\ First Online 15 November 2021

\section{Corresponding Author \\ Tel.: +905346472707 \\ E-mail: \\ ibrahimdogan0594@gmail.com}

\section{Keywords \\ AVGAS \\ Gasoline \\ Engine Power \\ Engine Torque \\ Direct Injection}

\begin{abstract}
AVGAS called is a high-octane fuel that is obtained by formulating Gasoline and called aviation Gasoline. Due to the high-octane level, the air-fuel mixture can be compressed at a higher rate without ignition. TSI, which consists of the initials of Turbo Supercharger Injection, is defined as a turbocharged and direct injection engine. Generally used in small volume engines such as $1.2 \mathrm{It}$. In this study, aviation Gasoline AVGAS and Gasoline were mixed in certain proportions and TSI was applied in a Gasoline engine. The changes in the performance of AVGAS-Gasoline fuel blends used in Direct Injection Engine were investigated in this experimental study. A5 (5\% AVGAS, $95 \%$ Gasoline fuel by volume), A10, and Gasoline fuel were used as fuel. The tests were performed at full-throttle valve opening and variable engine speeds. The results of the tests showed increases in engine power, engine torque values with the use of AVGASGasoline fuel blends, whereas, decrease was observed in brake specific fuel consumption values. While an increase of $1.54 \%$ was achieved in engine torque values compared to gasoline, the optimum values in engine power and specific fuel consumption were obtained as $51.92 \mathrm{~kW}$ at $3500 \mathrm{rpm}$ and $239 \mathrm{~g} / \mathrm{kWh}$ at $3000 \mathrm{rpm}$, respectively. In addition, increases were observed in the exhaust gas temperature and engine oil temperature, while a decrease was observed in the noise values.
\end{abstract}

\section{Introduction}

AVGAS is a high octane fuel obtained by formulating gasoline and called aviation gasoline. AVGAS is the type of aviation fuel used in small piston engine powered aircraft within the general aviation community (Atwood \& Rodgers, 2014; Chen et al., 2017). These aircraft are predominantly used by private pilots and flying clubs and for tasks such as flight training and crop dusting. Piston engines operate using the same basic principles as the spark ignition engines found in cars, but they have a much higher performance requirement. Octane number of AVGAS fuel is higher than the octane number of gasoline (Kumar et al., 2020; Rajendran \& Mohsin, 2018). Octane rating is a measure of how resistant a fuel is to knock; the higher the octane ratio, the more the fuel/air mixture can be compressed without ignition (Kumar et al., 2019; Rajendran \& Mohsin, 2018). The ratio of low and very volatile components in AVGAS is less than gasoline used in automobiles (Berry, 2009).

Knocking combustion study is critically significant due to the fact it decides engine longevity, gasoline usage, and energy density, along with noise and exhaust emission efficiency. Existing spark ignition (SI) engines encounter simultaneously conventional knock and super-knock (Prabakaran \& Viswanathan, 2018). 
Conventional knock restricts increase in the compression ratio to boost thermal performance caused by end-gas auto-ignition, whereas superknock restricts the ideal enhancement to increase the power density of present SI engines as a result of detonation. Knock is the term used to the sound linked with the auto-ignition of a section of the Gasoline-air combination in advance of the propagating flame front (Chen et al., 2017; Rajendran \& Mohsin, 2018). AVGAS is a knock resistant fuel (Thom \& Atwood, 2011).

In recent years, global restrictions have been imposed on the use of diesel vehicles due to their negative effects on the environment and human health (Palash et al., 2014; Prabakaran \& Viswanathan, 2018; Rajendran \& Mohsin, 2018). The developments experienced have attracted the attention of researchers and the studies to improve the properties of gasoline fuel have accelerated. There are very few studies in the literature on the use of AVGAS as a gasoline additive.

TSI, which consists of the initials of the words Turbo Spercharger Injektion, is defined as a turbocharged and direct injection engine. TSI engines are compact, high powered and use less fuel. Basically, the Volkswagen TSI engine uses a combination of turbocharging and direct fuel injection to deliver impressive and maximum benefits. With this technology, it is aimed to reduce engine volumes, to obtain greater power compared to engine volume, and to provide high fuel savings. When direct injection technology is combined with turbocharger technology, it is ensured that small engines produce high torque and horsepower exceeding their dimensions. With smaller designs and highly efficient combustion, TSI engines produce maximum power with minimum fuel consumption.

In this study, with using a Direct Injection (DI) engine the effects of AVGAS-Gasoline blends on engine performance were investigated.

The aim of the study is to investigate the engine performance and fuel consumption change compared to gasoline by using Avgas, which is a highly compressible fuel, in a TSI engine.

\section{Materials and Methods}

Fuel blends were prepared using AVGAS supplied by Airline Company and Gasoline supplied by Opet ( 95 Octane). Fuels containing $5 \%$ and $10 \%$ by volume of AVGAS are named $A 5$ and $A 10$, respectively. Fuel specifications are given in Table 1.

A 4-stroke, direct injection, and turbocharged 1.2 TSI engine was used as the test engine. Experiments were carried out for Gasoline, A5, and A10 fuels in the range of 1000 to $3500 \mathrm{rpm}$ with $500 \mathrm{rpm}$ increments. Experiments were carried out on the same day to prevent data deviations due to the difference in humidity and temperature in the atmosphere. In order to increase the reliability of the experimental results, the experiments were performed in three repetitions and the values were averaged. BT 190FR hydraulic dynamometer with $118 \mathrm{~kW}$ power and $750 \mathrm{Nm}$ torque capacity was used for the measurements. Test Engine specifications are given in Table 2 and test set-up is given in Figure 1.

Table 1. Fuel specifications.

\begin{tabular}{lccc}
\hline \multicolumn{1}{c}{ Spesifications } & Unit & $\begin{array}{c}\text { AVGAS } \\
\text { 100LL }\end{array}$ & Gasoline \\
\hline Engine octane number & MON & 99.5 & 85 \\
Research octane number & $\mathrm{RON}$ & 130 & 95 \\
Freezing point & ${ }^{\circ} \mathrm{C}$ & -58 & -45 \\
Boiling point & ${ }^{\circ} \mathrm{C}$ & 170 & 210 \\
Steam pressure & $\mathrm{kPA}$ & $38-49$ & $45-90$ \\
Sulfur content & $\mathrm{g} / \mathrm{kg}$ & 0.5 & 0.01 \\
Lead content & $\mathrm{g} / \mathrm{L}$ & 0.56 & 0.005 \\
Explosive limits & $\% \mathrm{Air}$ & $1.5-7.6$ & $1.3-7.1$ \\
Flash point & ${ }^{\circ} \mathrm{C}$ & -37 & -43 \\
Autoignition temperature & ${ }^{\circ} \mathrm{C}$ & 440 & 280 \\
Density & $\mathrm{kg} / \mathrm{m}^{3}$ & 720 & $720-775$ \\
Low Heat Value (LHV) & $\mathrm{kj} / \mathrm{kg}$ & 44.650 & 43.430 \\
\hline
\end{tabular}


Table 2. Test engine specifications

\begin{tabular}{cc}
\hline Definition & Specifications \\
\hline Model & 1.2 TSI, Direct Inj. \\
Total volume & $1197 \mathrm{~cm} 3$ \\
Number of cylinders & 4 \\
Compression ratio & $10: 1$ \\
Cylinder diameter & $71 \mathrm{~mm}$ \\
Stroke & $75.6 \mathrm{~mm}$ \\
Turbocharge pressure & $160 \mathrm{kPa}$ (at 3500 rpm)
\end{tabular}

\section{Results and Discussion}

The test results of AVGAS blended fuels are compared with the results of the gasoline reference fuel in the graphs below.

Depending on the engine speed ranges; Engine torque changes due to gasoline, A5, and A10 fuels are shown in Figure 2. As seen in the figure, the maximum moment values in all fuels were approximately at 3500 $\mathrm{rpm}$. The highest engine torque value was obtained with A10. The lowest value was obtained from gasoline at $1000 \mathrm{rpm}$. In all three different fuel mixtures, it was determined that the engine torque at $3500 \mathrm{rpm}$ increased $\mathrm{A} 5$ by $1.11 \%$ and $\mathrm{A} 10$ by $1.54 \%$, respectively, compared to gasoline.

Depending on the engine speed ranges; the engine power changes due to gasoline, A5, and A10 fuels are shown in Figure 3. Engine power increased with increasing engine speed for all fuels tested. Maximum engine power values for all fuel blends are measured at $3500 \mathrm{rpm}$. The highest engine power value was measured as $51.92 \mathrm{~kW}$ in A10 fuel. In Gasoline, the highest engine power value is $50.99 \mathrm{~kW}$. AVGAS use showed an increase of approximately $1.82 \%$ in engine power compared to gasoline. In A5 fuel, it was measured as $51.1 \mathrm{~kW}$.

The lower calorific value of AVGAS is higher than Gasoline (Air BP Ltd.,2019; Rajendran \& Mohsin, 2018). For this reason, the increase in engine power is thought to occur from higher combustion efficiency and better atomization characteristics due to the increase in the lower calorific value of the fuel. In addition, thanks to the Tetraethyllead (TEL) additive in AVGAS, the ignition and combustion quality of the fuel have improved, resulting in an increase in engine power (Atwood \& Rodgers, 2014).

Depending on the engine speed ranges; exhaust gas temperature changes due to gasoline, A5 and A10 fuels are shown in Figure 4. The exhaust gas temperature increased with the increase of engine speed for all fuels tested. The lowest exhaust gas temperature was obtained from gasoline as $208^{\circ} \mathrm{C}$ at $1000 \mathrm{rpm}$. In other fuels, as the AVGAS ratio increased, the exhaust gas temperature increased. While the highest exhaust gas temperature values are $613^{\circ} \mathrm{C}$ in gasoline at $3500 \mathrm{rpm}$, it is $645^{\circ} \mathrm{C}$ in the $A 10$ fuel mixture.

Since the lower calorific value of AVGAS is higher than gasoline, it can be said that the temperature inside

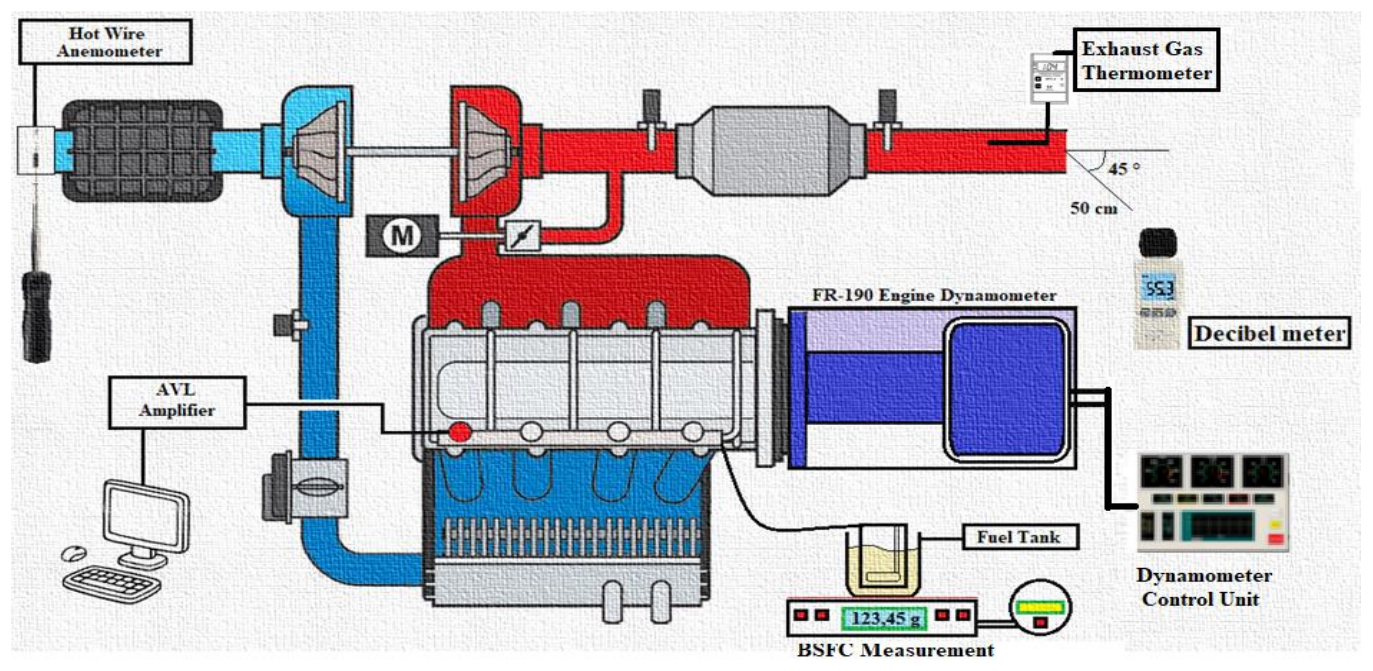

Figure 1. Test Setup. 


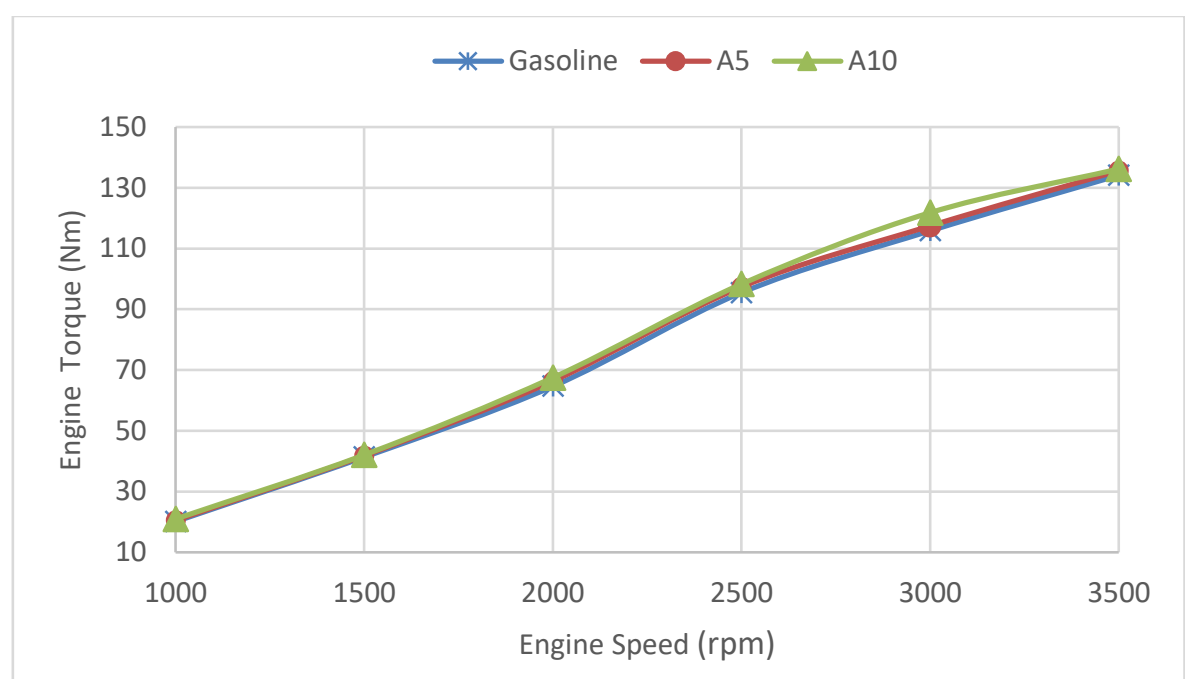

Figure 2. Graph of engine torque test responses.

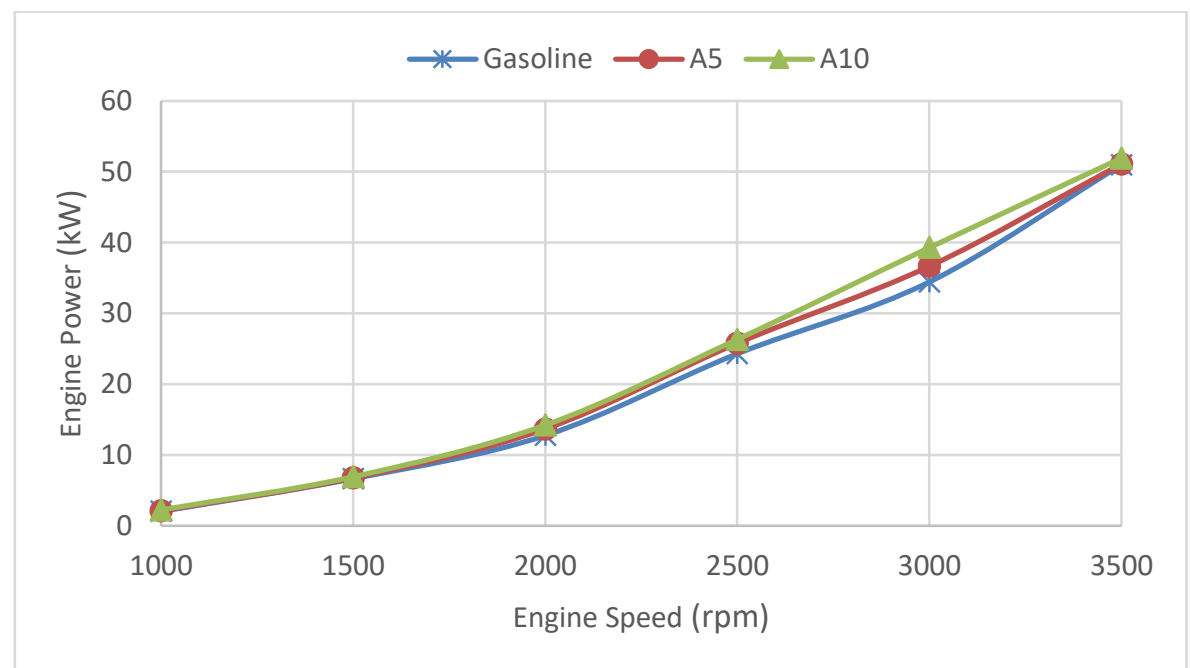

Figure 3. Graph of engine power test responses.

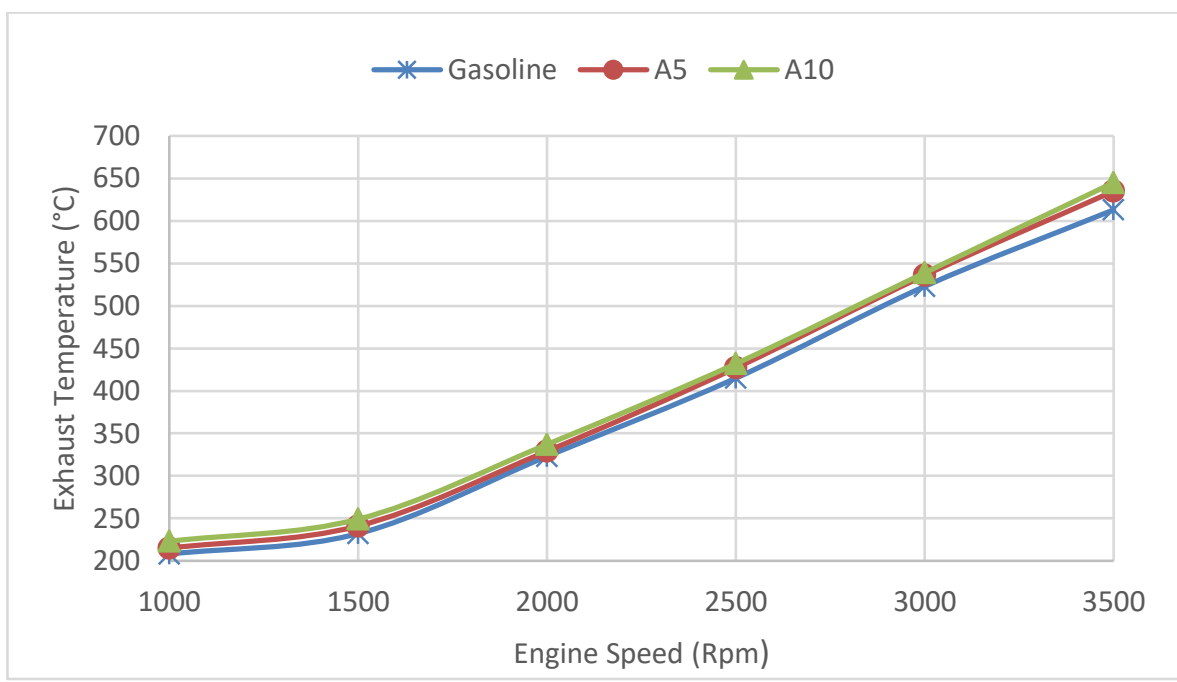

Figure 4. Graph of exhaust gas temperature test responses. 
the cylinder is also high (Atwood \& Rodgers, 2014). Therefore, the use of AVGAS has increased the exhaust gas temperature.

Depending on the engine speed ranges; The engine oil temperature changes due to gasoline, A5, and A10 fuels are shown in Figure 5 . The lowest engine oil temperature was measured as $83.5^{\circ} \mathrm{C}$ in gasoline at $1000 \mathrm{rpm}$. For other fuels, respectively, the lowest engine oil temperatures are at $1500 \mathrm{rpm}$; It measured $86.6^{\circ} \mathrm{C}$ in $\mathrm{A} 5$ fuel and $87.3^{\circ} \mathrm{C}$ in $\mathrm{A} 10$ fuel. The use of AVGAS has increased the engine oil temperature. The highest engine oil temperatures were measured as $105.7^{\circ} \mathrm{C}$ in gasoline at $3500 \mathrm{rpm}$ and $108.7^{\circ} \mathrm{C}$ in A10 fuel mixture.

Depending on the engine speed ranges; noise changes due to gasoline, $A 5$, and $A 10$ fuels are shown in Figure 6 . The noise increased in all fuels tested with increasing engine speed. The lowest noise value was measured as $80.9 \mathrm{~dB}$ in the $\mathrm{A} 10$ fuel mixture at 1000 rpm. In gasoline, it is $83.1 \mathrm{~dB}$ at the same speed.
The highest noise values at $3500 \mathrm{rpm}$, respectively; $103.1 \mathrm{~dB}$ in gasoline, $102.7 \mathrm{~dB}$ in $\mathrm{A} 5$ fuel, and $102.3 \mathrm{~dB}$ in A10 fuel. The use of AVGAS has reduced the noise values.

Depending on the engine speed ranges; specific fuel consumption changes due to gasoline, A5, and A10 fuels are shown in Figure 7. The lowest specific fuel consumption values were measured at $3000 \mathrm{rpm}$, respectively, $239 \mathrm{~g} / \mathrm{kWh}$ in A10 fuel mixture, $246 \mathrm{~g} / \mathrm{kWh}$ in A5 fuel mixture, and $263 \mathrm{~g} / \mathrm{kWh}$ in gasoline. Specific fuel consumption decreased up to $3000 \mathrm{rpm}$ and increased again after this cycle. The use of AVGAS, on the other hand, reduced the specific fuel consumption. This is because the lower calorific value of AVGAS is higher than gasoline. There is an inverse proportion between lower calorific value and specific fuel consumption (Palash et al., 2014). As the lower calorific value increases, the specific fuel consumption decreases. Due to the lower calorific value of gasoline, more fuel is used to provide the same power.

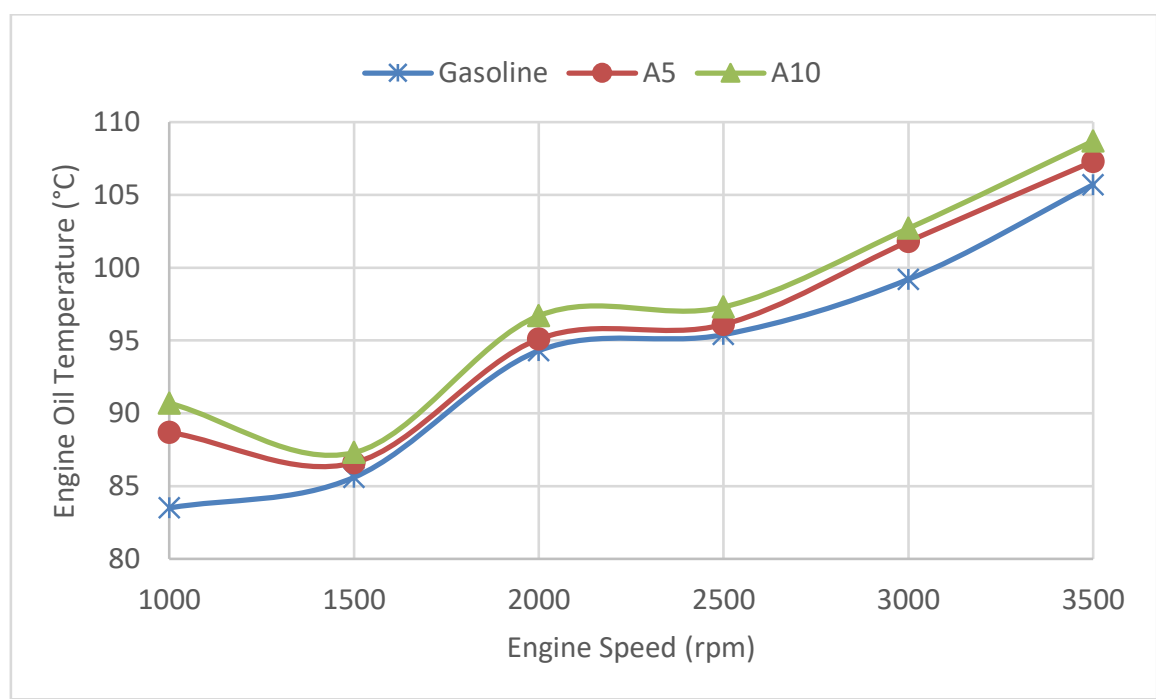

Figure 5. Graph of engine oil temperature test responses.

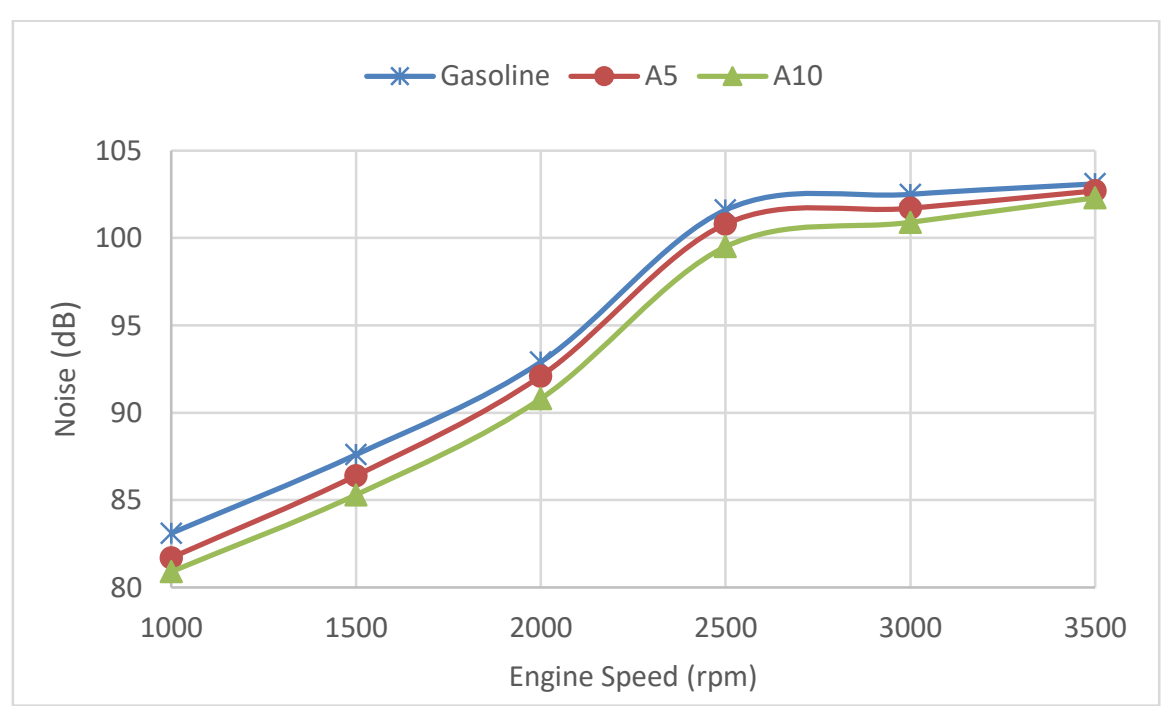

Figure 6. Graph of noise test responses. 


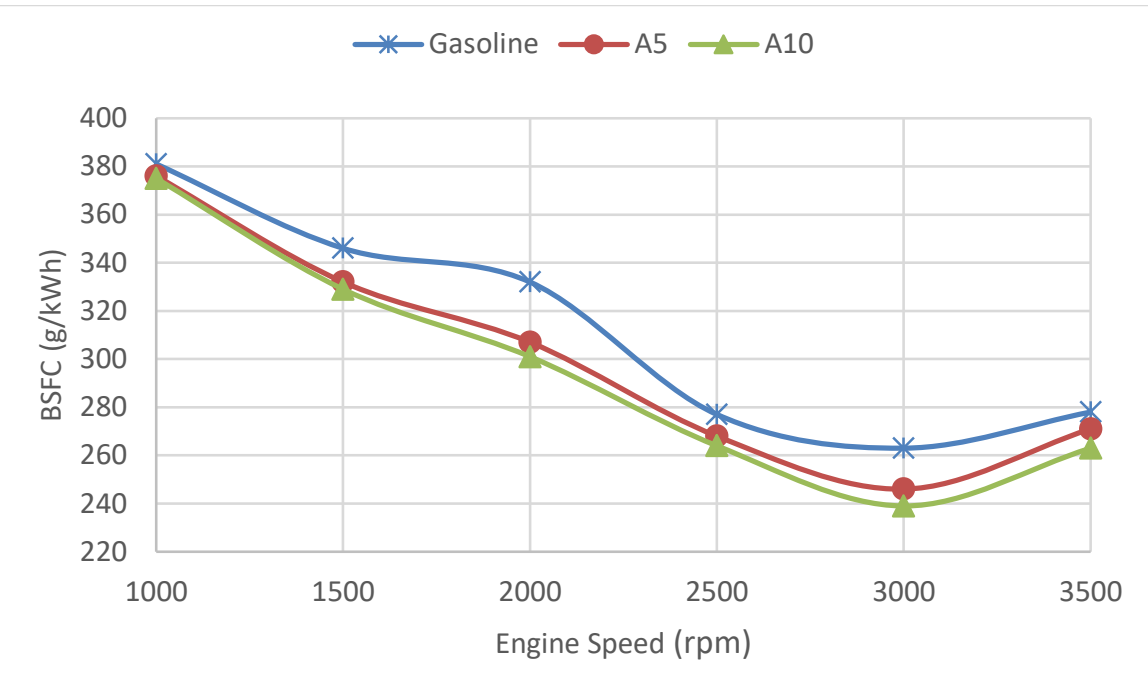

Figure 7. Graph of specific fuel consumption test responses.

\section{Conclusion}

In this study, mixtures obtained by adding $5 \%$ and $10 \%$ AVGAS volumetrically to gasoline and gasoline were tested in a gasoline engine with direct injection at constant load and different engine speeds. According to the results;

- $\quad$ Engine torque and engine power increased in all test fuels as engine speed increased. It has been observed that the use of AVGAS also increases these values. Exhaust gas temperature and engine oil temperature increased with the use of AVGAS and engine speed.

- With the increase of engine speed, the noise level increases in all test fuels, but it has been observed that the noise level decreases with the use of AVGAS.

- In the specific fuel consumption, while a decrease was seen in all fuels up to $3000 \mathrm{rpm}$, it started to increase again after this cycle. The use of AVGAS, on the other hand, has been found to reduce specific fuel consumption.

- The use of AVGAS in gasoline has generally yielded positive results in engine performance parameters. The reason for the increase in temperature values can be explained by the fact that it allows high compression and its lower calorific value is higher than gasoline.

\section{References}

Air BP Ltd. (2019). The dedicated aviation fuel. https://www.bp.com/content/dam/bp/businesssites/en/global/air-bp/documents/aviation-fuel/air-bpavgas-3rd-a4-leaflet-uk-2019.pdf

Atwood, D., \& Rodgers, M. (2014). Anti-knock performance of reduced lead aviation gasoline in a full-scale engine. Springfield, Virginia, 22161.

http://www.tc.faa.gov/its/worldpac/techrpt/tc1410.pdf
Berry, M. (2009). Autogas vs Avgas. http://www.avgas.pl/files/Autogas\%20vs\%20Avgas.pdf Chen, L., Ding, S., Liu, H., Lu, Y., Li, Y., \& Roskilly, A.P. (2017). Comparative study of combustion and emissions of kerosene (RP-3), kerosene-pentanol blends and diesel in a compression ignition engine. Applied Energy, 203, 91100. https://doi.org/10.1016/j.apenergy.2017.06.036

Kumar, T., Mohsin, R., Majid, Z.A., Ghafir, M.F. A., \& Wash, A.M. (2020). Experimental study of the anti-knock efficiency of high-octane fuels in spark ignited aircraft engine using response surface methodology. Applied Energy, 259, 114150. https://doi.org/10.1016/j.apenergy.2019.114150

Kumar, T., Mohsin, R., Majid, Z.A., Ghafir, M. F.A., Yusuf, N.K., Kim, J., Wash, A. M., \& Sahri, D.M. (2019). Response surface methodology application in optimization of performance and exhaust emissions of RON 98, aviation gasoline $100 \mathrm{LL}$ and the blends in Lycoming 0-320 engine. Fuel, 256, 115909. https://doi.org/10.1016/j.fuel.2019.115909

Palash, S., Kalam, M., Masjuki, H., Arbab, M., Masum, B., \& Sanjid, A. (2014). Impacts of NOx reducing antioxidant additive on performance and emissions of a multicylinder diesel engine fueled with Jatropha biodiesel blends. Energy Conversion and Management, 77, 577585. https://doi.org/10.1016/j.enconman.2013.10.016

Prbakaran, B., \& Viswanathan, D. (2018). Experimental investigation of effects of addition of ethanol to biodiesel on performance, combustion and emission characteristics in $\mathrm{Cl}$ engine. Alexandria Engineering Journal, 57(1), 383-389. https://doi.org/10.1016/j.aej.2016.09.009

Rajendran, Y., \& Mohsin, P.D.R. (2018). Emission due to motor gasoline fuel in reciprocating lycoming 0-320 engine in comparison to aviation gasoline fuel. Environment \& Ecosystem Science, 2(2), 20-24. https://doi.org/10.26480/ees.02.2018.20.24

Thom, M., \& Atwood, D. (2011). Review of certificates of analysis and test data of aviation gasoline for current ranges of lead additive. Springfield, Virginia, 22161. http://www.tc.faa.gov/its/worldpac/techrpt/artn1120.pdf 